\title{
Seeing the strings
}

\author{
Rebecca Coombes magazine editor, The BMJ
}

In The BMJ's London office hangs a puppet on a string: a bespectacled doctor. It was used on a past journal cover to illustrate key opinion leaders (www.bmj.com/content/336/7658). The inference is that doctors who are paid by drug companies to advise on marketing strategies, present at conferences, or write in medical journals are puppets, whose message is controlled by their commercial paymasters.

Our cover story this week also deals with payments to doctors (BMJ 2014;349:g4601, doi:10.1136/bmj.g4601). As Clare Dyer explains, this is not remuneration for the day job but additional income. This extra cash can take many forms: sponsorship to attend or speak at meetings or membership of an advisory board. Some doctors may own or have shares in a company that provides medical services. We already know that these benefits and financial interests, especially if undisclosed, can lead to bias in treatment decisions, and The BMJ has long campaigned that transparency is the best antidote.

In recent years we have begun to get a sense of the scale of the problem, as legislation and reputational damage have forced drug companies to publish data on their payments to doctors (BMJ 2013;346:f615, doi:10.1136/bmj.f615; BMJ

2012;344:e515, doi:10.1136/bmj.e515). So now we know that the world's top 12 drug manufacturers paid US doctors \$1bn ( $£ 0.6$ bn; $€ 0.7 b n$ ) in 2012 . In the same year UK companies paid 21000 unnamed clinicians around $£ 40 \mathrm{~m}$.

As a next step on the path towards total transparency, from 2016 the Association of British Pharmaceutical Industries will publish the names of doctors paid by member companies and the amounts. US drug and device companies will do the same thing even earlier, from September this year.

But why rely on disclosures by drug companies, which are not the only source of doctors' financial conflicts of interests?

Doctors may, for example, be shareholders in a company that provides diagnostic or pathology services to which their patients might be referred. Wouldn't it be better if doctors had to disclose their financial conflicts of interest on a public register, perhaps as part of their annual appraisal? In the UK, the General Medical Council told Dyer that this is now "a work in progress." Do vote in our poll on thebmj.com this week to show where you stand on this issue.

It's true that journalists will mine disclosures for stories, and doctors will come under greater pressure to think about their conflicts of interests. But doctors are the middle men and women. Patients need full disclosure to make up their own minds about whether treatment decisions might be affected by their doctors' commercial interests. They need to see the "strings." So too do fellow doctors who rely on senior colleagues for learning, advice, and guidance. Perhaps then, when the strings are visible to all, doctors will be less willing to get tied up in the first place.

Also in the journal this week our Too Much Medicine series takes on pre-diabetes (BMJ 2014;349:g4485, doi:10.1136/bmj. g4485), which opens with a quote from Aldous Huxley:

"Medical science has made such tremendous progress there is hardly a healthy human left." This is nowhere better illustrated than in China. If implemented globally, say Yudkin and Montori, the latest US guidelines would create an epidemic, with over half of Chinese adults having pre-diabetes, a national burden of around 493 million people.

And what of too much medicine at the end of life? In Letters (BMJ 2014;349:g4584, doi:10.1136/bmj.g4584), the general practitioner Caroline Mawer responds to an opinion article about the futility of cardiopulmonary resuscitation in some dying patients. Mawer's stated competing interests? "When my dad died from metastatic cancer, no one attempted CPR. Instead, I kissed him, told him I loved him, and laid down beside him."

Follow Rebecca Coombes at twitter.com/rebeccacoombes

Cite this as: BMJ 2014;349:94657

๑ BMJ Publishing Group Ltd 2014 